\title{
Intraspecific morphological variation of the scorpionfly Dicerapanorpa magna (Chou) (Mecoptera: Panorpidae) based on geometric morphometric analysis of wings
}

\author{
Mei Liu ${ }^{1}, \mathrm{Na} \mathrm{Ma}^{1,2}$, Bao-Zhen Hua ${ }^{1,3}$ \\ ${ }^{1}$ State Key Laboratory of Crop Stress Biology for Arid Areas, Entomological Museum, Northwest A\&F University, \\ Yangling, Shaanxi 712100, China \\ ${ }^{2}$ School of Agricultural Engineering, Henan Provincial Key Laboratory of Funiu Mountain Insect Biology, Nanyang \\ Normal University, Nanyang, Henan 473061, China \\ ${ }^{3}$ E-mail: huabzh@nwafu.edu.cn
}

Key words: canonical variates analysis, individual variation, sexual dimorphism

\begin{abstract}
Wing shape variation was investigated between the sexes and among four populations of the scorpionfly Dicerapanorpa mag$n a$ (Chou, 1981) endemic to the Qin-Ba Mountains area, China through the landmark-based geometric morphometric approach. The results show that sexual dimorphism exists both in wing size and shape in D. magna. Significant differences exist in female wing size and shape among D. magna populations. The possible reasons of the wing variation are discussed based on the divergence time of $D$. magna in combination with the tectonic and climatic events in the Qin-Ba Mountains during the late Miocene-Pleistocene period. Whether reproductive isolation exists between different populations needs further research.
\end{abstract}

\section{Contents}

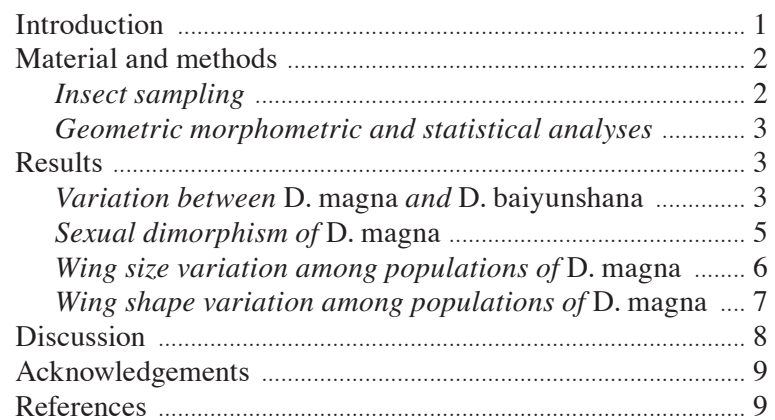

\section{Introduction}

Morphological variation is prevalent in wide-ranging species (Mayr, 1963) and is related to phenotypic plasticity, physiological response to environmental factors and adaptation to local environments and divergent selection, potentially leading to speciation through the evolution of reproductive barriers (McPeek, 1990;
Stillwell et al., 2005; Neto et al., 2013). Morphological variation provides a major source of characters and character states in traditional taxonomy (Michaux, 1989; McPeek, 1990). However, it is often difficult to determine whether variation is intraspecific or interspecific in taxonomic practice (Nedeljković et al., 2013; Riedel et al., 2013; Barão et al., 2014).

Landmark-based geometric morphometrics is an effective tool to quantify and analyze the overall shape of biological structures based on two- or three-dimensional Cartesian coordinates of landmarks (Bookstein, 1991; Adams et al., 2013). It has been widely applied in insect taxonomy and systematics to detect subtle morphological variation (Francuski et al., 2009; Baracchi et al., 2011; Neto et al., 2013; Pepinelli et al., 2013), which is often undetectable with classical morphometric methods (Zelditch et al., 2004).

Insect wings are two-dimensional flattened structures that bear many homologous landmarks and are suitable for geometric morphometric analysis (Grodnitsky, 1999; Zelditch et al., 2004). They have been successfully used to resolve taxonomic problems in closely related species groups (Palmer, 2004; Aytekin et al., 2007; Baracchi et al., 2011; Neto et al., 2013; Barão et al., 2014) and to discriminate populations within a species (Haas and Tolley, 1998; Pepinelli et al., 2013).

The scorpionflies Panorpidae (Insecta: Mecoptera) usually live in large populations in moist forested habitats (Byers and Thornhill, 1983). Since the adults are relatively weak fliers (Thornhill, 1980; Byers and Thornhill, 1983), gene exchange between discrete populations is greatly limited, if not completely broken off. In this case, morphological variation is prevalent in Panorpidae, especially the wing markings and genitalia (Ward, 1979, 1983; Jones, 2010; Ma et al., 2014). 


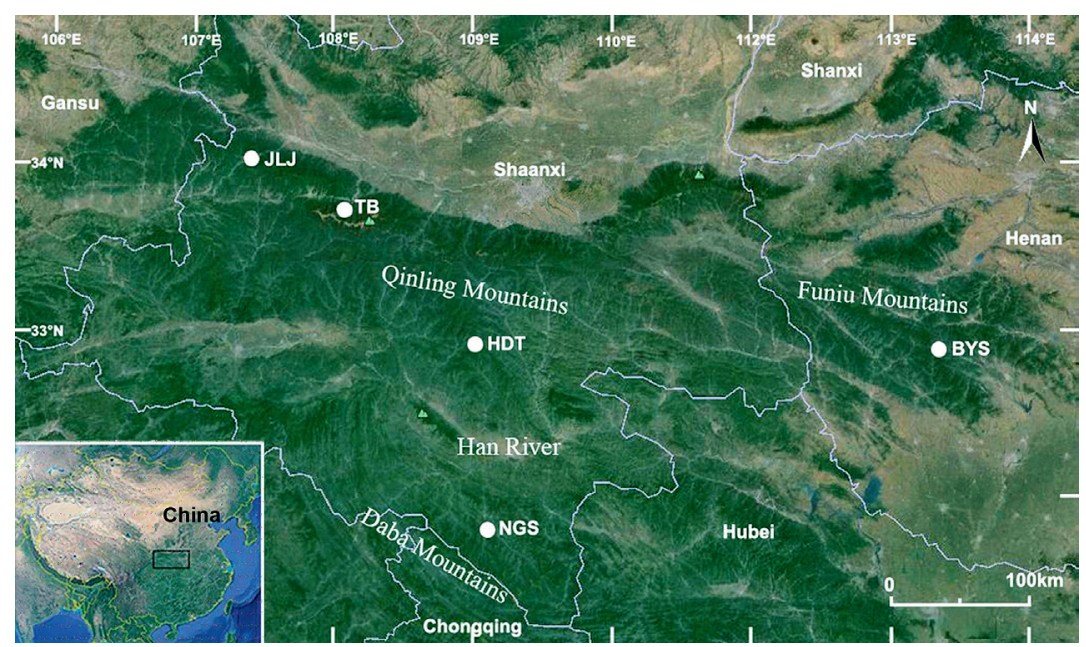

Fig. 1. Localities of the populations analyzed: JLJ (Jialingjiang Source Forest Park, Shaanxi); TB (Mt. Taibai, Shaanxi); HDT (Huoditang Forest Farm, Shaanxi); NGS (Nangongshan National Forest Park, Shaanxi); BYS (Baiyunshan, Henan).

The Qin-Ba Mountains area is composed of the Qinling Mountains and Daba Mountains in central China (Liang, 2002). These two mountains are continuous and are divided by the Hanshui River and a series of basins. The Qinling Mountains are the prominent boundary between the Oriental and Palearctic Regions in China and are rich in the biodiversity of Mecoptera (Chou et al., 1980; Ying, 1994; Yuan et al., 2012).

Dicerapanorpa magna (Chou in Chou et al., 1981) was originally described based on a female holotype collected from Huoditang at the southern slope of the Qinling Mountains. Later, this scorpionfly species was found to be widely distributed in the Qin-Ba Mountains (Hua and Chou, 1997; Nie and Hua, 2004). Previous research reveals that individuals of $D$. magna from different areas exhibit variation both in external morphology and internal anatomy, including the number of female ovarioles and male salivary gland tubes (Hou and Hua, 2008; Ma et al., 2011). This led us to hypothesize whether these variations are intraspecific or interspecific.

In this paper, different populations of D. magna collected from the Qin-Ba Mountains were examined using landmark-based geometric morphometrics to quantify wing size and shape variations between the sexes and among allopatric populations.

\section{Material and methods}

\section{Insect sampling}

To assess intra- and interspecific variation of D. magna, the closely related species D. baiyunshana Zhong \& Hua, 2013 was included included in the analysis. Owing to limited sample size of $D$. baiyunshana males, interspecific analysis of wing variations was conducted only for females. Ten female specimens of D. baiyunshana were collected from Baiyunshan (BYS, 1300 $\mathrm{m})$, Henan Province in 2001. Specimens of D. magna (76 males and 172 females) were collected from four regions in Shaanxi Province from June to August in 2013, including 24 males and 48 females from the Huoditang Forest Farm (HDT, 1500-1800 m), 22 males and 40 females from the Jialingjiang Source Forest Park (JLJ, 1500-1700 m), 8 males and 44 females from

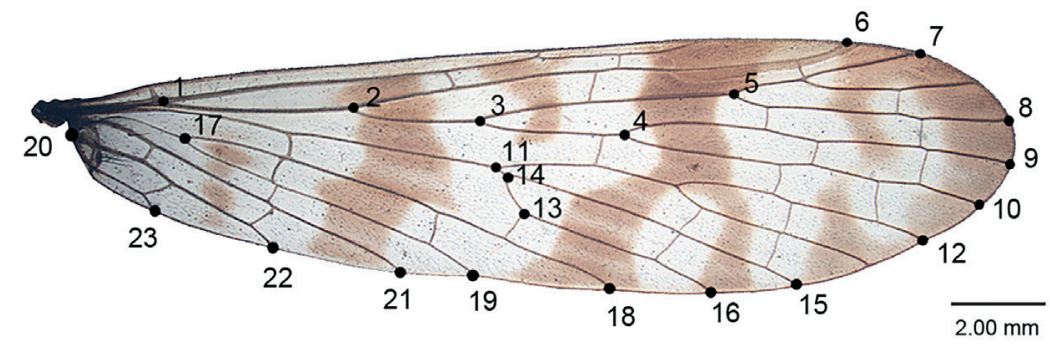

Fig. 2. Right forewing of D. magna, showing the landmarks used in this study. 
Nangongshan National Forest Park (NGS, 1700-1800 $\mathrm{m}$ ), and 22 males and 40 females from Mt. Taibai (TB, 2300-2500 m). The localities of populations analyzed are marked on the map (Fig. 1).

\section{Geometric morphometric and statistical analyses}

Right forewings were carefully removed from $75 \%$ alcohol-preserved specimens and temporarily mounted on micro-slides. Photographs with the same scale were taken with a digital camera attached to the Nikon SMZ1500 stereo zoom microscope (Nikon, Tokyo, Japan).

Twenty-three homologous landmarks (LMs) at vein intersections or terminations that could be reliably identified were selected (Fig. 2), and can be considered type I landmarks (Bookstein, 1991). Data for wing size and shape were obtained by positioning landmarks on digitized wings using tpsDig2 (Rohlf, 2004).

Measurement error. An analysis of measurement error was conducted on a subsample of 30 specimens of D. magna, which were chosen randomly and repeated 2 times to obtain landmark data. Procrustes ANOVA (analysis of variance) was performed for landmark data in MorphoJ v1.05c (Klingenberg and McIntyre, 1998; Klingenberg, 2011). All measurements were taken by the same person to reduce experimenter effect. The averaged error of wing centroid size did not exceed $0.18 \%$ of the total variation $(F=0.01, P=1.0000)$, and $0.49 \%(F=0.12, P=1.0000)$ for wing shape variables. This means that the measurement error explained a negligible percentage of variance.

Size variation. Wing size variation was examined using centroid size (the square root of the sum of squared distance between each landmark and the wing centroid), which was uncorrelated with any shape variable and was not influenced by landmark variation (Bookstein, 1991, 1996). Centroid size was calculated using tpsRelw 1.44 (Rohlf, 2006) and tested for normality using the Shapiro-Wilk test. Leven's test was used to test homogeneity of the variance (Milliken and Johnson, 2009). One-way analysis of variance (ANOVA) was used to test the difference in centroid size between the sexes and among populations. A post hoc test (LSD test) after Bonferroni correction on centroid size defined pair-wise differences in centroid size of populations. All statistical analyses were performed in IBM SPSS statistics software version 19.0 for windows (IBM Corporation, 2010).

Shape variation. For wing shape variation, the 258 landmark configurations were scaled, translated, and rotated against the consensus configuration using Generalized Procrustes Analysis (GPA) procedure to remove the nonshape effects of size, position and orientation (Rohlf and Slice, 1990; Dryden and Mardia, 1998). The resulted matrix ( $w$; 'weight matrix' sensu Rohlf et al., 1996) was used for shape analysis. For a shape, a principal component analysis (PCA) was carried out to determine the explained percentage of each principal component (PC) of the total variation. The total shape variables were used for the multivariate analysis of variance (MANOVA) to test wing shape differences within and among species/population. Canonical variate analysis (CVA) and linear discriminant analysis (LDA) were used to discriminate populations and provide shape variations associated with canonical variates (CVs). The percentages of correct classification (hit ratio, HR sensu Gerard et al., 2015; Huberty and Olejnik, 2006) based on a leave-one-out cross-validation procedure in LDA were used to evaluate the discriminatory power of the wing. The allometric effect or the change in shape associated with size differences was evaluated with a multivariate regression of shape variables onto size. Morphometric and statistical analyses were computed using the IMP series software (Sheets, 2012), MorphoJ v1.05c (Klingenberg, 2011) and R version 3.0.2 (R Core Team, 2013).

\section{Results}

Variation between D. magna and D. baiyunshana

The Shapiro-Wilk test revealed that centroid sizes of all populations show a normal distribution $(P>0.05)$. Leneve's test showed a significant homogeneity of variances $(F(1,266)=2.530, P=0.113>0.05)$ based on mean centroid sizes. A one-way ANOVA of mean centroid sizes of wings showed highly significant differences among all the analyzed populations $(F(8,259)=$ $29.104, P=0.000)$. The result of LSD as a post hoc test after Bonferroni correction on centroid size showed that $D$. baiyunshana bears the largest centroid size (Fig. 3) and differs significantly from all D. magna populations studied $(P=0.000)$ (Table 1$)$.

In order to discriminate taxa at the interspecific level, we used only the females to avoid the effect of sexual dimorphism. The twenty-three landmarks yield 42 shape variables, and accordingly 42 PCs. Each PC had progressively less variance, with PC1 (18.9\%) and PC2 (15.9\%) representing more than $34 \%$ of the total variance (Fig. 4). Most specimens from BYS are clustered 


\begin{tabular}{|c|c|c|c|c|c|c|c|c|}
\hline & HDTô & JLJ $0 \widehat{~}$ & NGS $\widehat{0}$ & TB $\widehat{0}$ & HDT우 & JLJ우 & NGS 9 & $\mathrm{~TB} q$ \\
\hline JLJồ & 0.086 & & & & & & & \\
\hline NGS $\widehat{\varnothing}$ & 0.247 & 0.145 & & & & & & \\
\hline TB $0^{\hat{n}}$ & 0.206 & 0.654 & 0.075 & & & & & \\
\hline HDTㅇ & $0.000 *$ & $0.000^{*}$ & $0.000 *$ & $0.000 *$ & & & & \\
\hline JLJㅇ & $0.000 *$ & $0.000 *$ & $0.000^{*}$ & $0.000 *$ & 0.417 & & & \\
\hline NGS 9 & $0.000 *$ & $0.000 *$ & $0.000^{*}$ & $0.000 *$ & $0.000^{*}$ & $0.001^{*}$ & & \\
\hline TB우 & $0.000 *$ & $0.000 *$ & $0.000^{*}$ & $0.000 *$ & 0.859 & 0.344 & $0.003^{*}$ & \\
\hline BYS $q$ & $0.000 *$ & $0.000 *$ & $0.000^{*}$ & $0.000^{*}$ & $0.000^{*}$ & $0.000^{*}$ & $0.000^{*}$ & $0.000^{*}$ \\
\hline
\end{tabular}

Table 1. Pair-wise ANOVA on wing centroid size of D. baiyunshana (BYS) and D. magna populations (HDT, JLJ, NGS, and TB). * Significant differences, the adjustment of $P$-value after Bonferroni correction is $<0.006$.

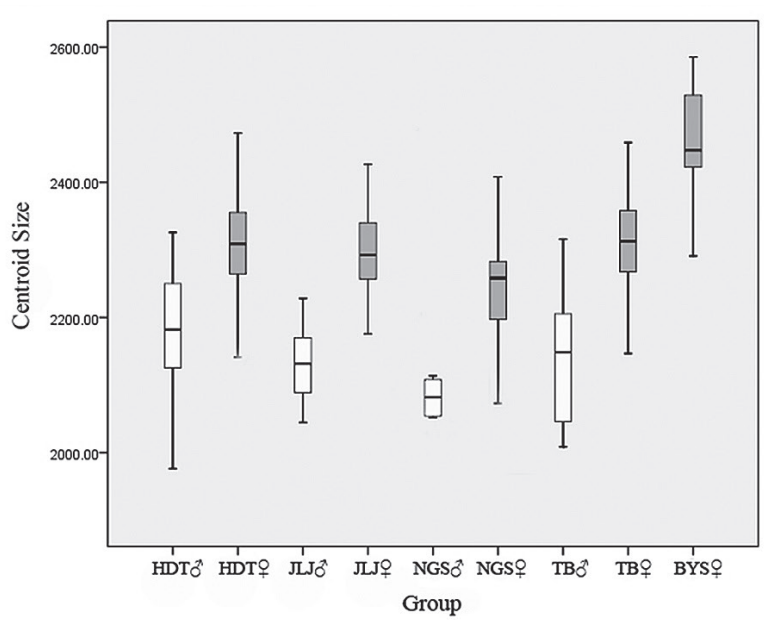

Fig. 3. Boxplot of centroid size of D. baiyunshana (BYS) and D. magna populations (HDT, JLJ, NGS, and TB). White (male), grey (female).

together with D. magna populations on the right of the scatter plots (Fig. 4). Shape variation associated with the first PC reflected a construction of distal and posterior margins of the wing and anterior furcation of veins Sc and R. The second PC represented an expansion of the anterior, distal and posterior margins of the wing, and a construction of the basal part of the wing (Fig. 4).

The shape analysis revealed that the shape variation exists between $D$. baiyunshana and four different populations of $D$. magna (MANOVA: $F(4,177)=3.68 ; P$ $<0.0001)$. CV1 (40.3\%, Wilks' $\lambda=0.0372 ; P<0.001)$ and CV2 (27.3\%, Wilks' $\lambda=0.1183 ; P<0.001)$ accounted for $67.6 \%$ of total shape variation, clearly separating $D$. baiyunshana individuals from all $D$. magna specimens (Fig. 5). Shape changes associated with CV1 explained the most discrimination between species, representing a construction of anterior margin and an expansion of posterior margin of the wing. CV2 also involved in a construction of anterior margin of the wing (Fig. 5).

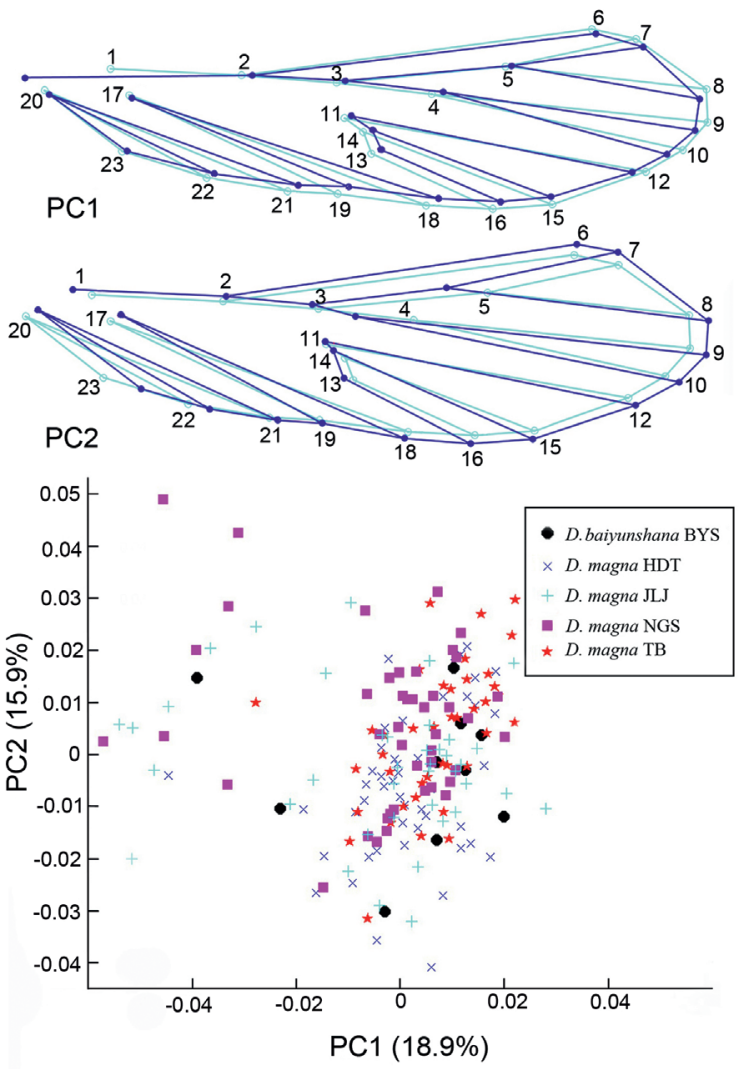

Fig. 4. Scatter plots of $\mathrm{PC} 1$ versus $\mathrm{PC} 2$ for D. baiyunshana (BYS) and D. magna populations (HDT, JLJ, NGS, and TB). Deformation grids illustrate the shape variations associated with PC1 and PC2. A dark blue wireframe graph (solid dots) is compared with the overall mean shape (bright blue, open dots).

The assignment by the cross-validation in LDA showed that $87 \%$ specimens were correctly assigned to their group (Table 2). Ten individuals of D. baiyunshana showed an HR of $100 \%$. Four of HDT were misclassified, two being assigned to NGS and two to TB (HR 92\%). Among 40 JLJ specimens, one was misclassified as HDT, three as NGS, and four as TB (93\%). Among 44 NGS specimens, one was misclassified as 


\begin{tabular}{llrrrrr}
\hline & BYS & HDT & JLJ & NGS & TB & HR\% \\
\hline BYS & 10 & & & & & $100 \%$ \\
HDT & & 44 & 1 & 1 & 2 & $92 \%$ \\
JLJ & & & 37 & & 3 & $93 \%$ \\
NGS & 2 & 3 & 37 & 2 & $84 \%$ \\
TB & 2 & 6 & 4 & 28 & $70 \%$ \\
\hline
\end{tabular}

Table 2. Specimen assignment using the "leave-one-out" procedure in the LDA of D. baiyunshana (BYS) and D. magna populations (HDT, JLJ, NGS, and TB). Original groups are along the rows, predicted groups are along the columns. The hit ratio (HR\%) is also given for each groups.
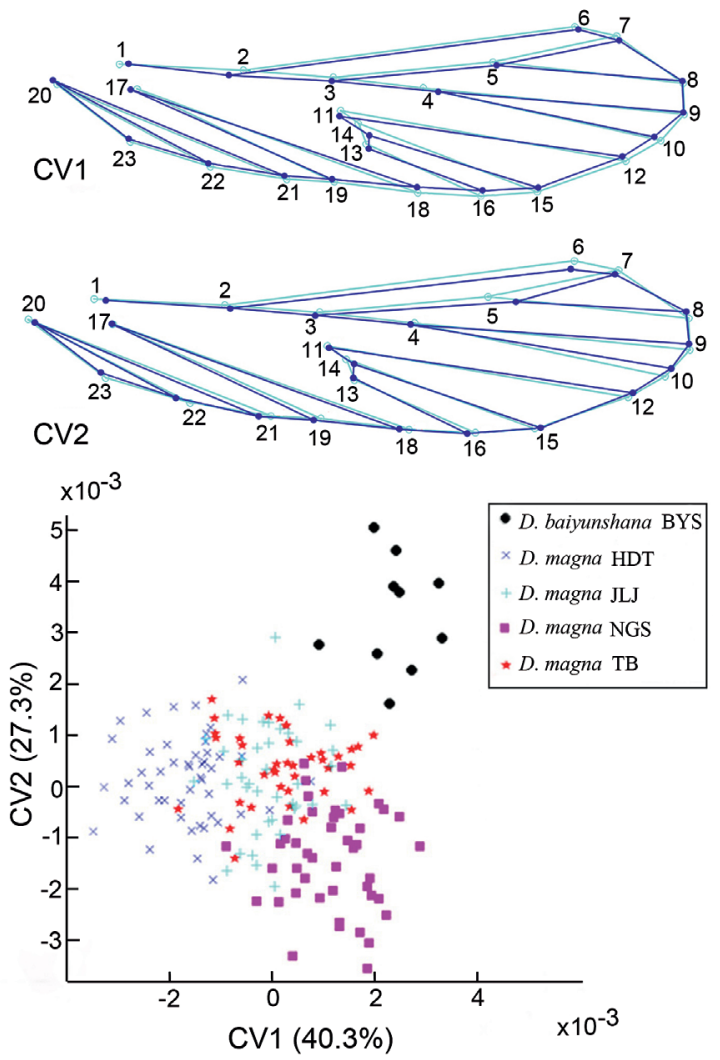

Fig. 5. CVA scatter plots of females of D. baiyunshana (BYS) and D. magna populations (HDT, JLJ, NGS, and TB). Shape changes associated with CV1 and CV2 are shown. A dark blue wireframe graph (solid dots) is compared with the overall mean shape (bright blue, open dots).

HDT and four as TB (HR 84\%). Twelve of TB were misclassified, two being assigned to HDT, four to NGS, and six to TB (70\%) (Table 2).

\section{Sexual dimorphism of $\mathrm{D}$. magna}

The ANOVA analysis showed that the female wings bear larger centroid sizes than the males $(F(1,246)=$
$117.2 ; P=0.000$ ), and pair-wise ANOVA after Bonferroni correction on centroid size showed significant differences between the sexes of D. magna populations (Table 1), exhibiting sexual dimorphism of wing size in D. magna (Fig. 3).

In PCA, the first three PCs accounted for $54.49 \%$ $(28.29 \%+16.64 \%+9.56 \%)$ of total shape variation, and provided a reasonable estimation of the total variation. The other PCs each accounted for no more than $6.7 \%$ of the variation. The scatter plots of PC1 and PC2 showed that the males cluster together on the left, whereas the females are on the right of the scatter plots, with a little overlap (Fig. 6). Shape variation along PC1 represented a construction of the distal part of the wing and anterior furcation of veins Sc and R. PC2 showed an elongation of the distal part of the wing, anterior furcation of $\mathrm{Sc}$ and $\mathrm{R}$ and a construction of anterior and posterior margins of the wing (Fig. 6).

Sexual dimorphism exists in wing shape of $D$. mag$n a$ populations (MANOVA: $F(7,240)=5.686 ; P<$ 0.0001). CV1 (43.54\%, Wilks' $\lambda=0.0219 ; P<0.001$ ) and CV2 $(18.49 \%$, Wilks' $\lambda=0.0789 ; P<0.001)$ accounted for $62 \%$ of the total shape variation. The males and females were clearly separated from each other in the CVA scatter plots (Fig. 7). Shape changes associated with CV1 illustrated the most of discrimination, including an elongation of the distal and basal parts of the wing, and posterior furcation of veins $\mathrm{Sc}$ and $\mathrm{R}$. CV2 represented a construction of the anterior part of the wing (Fig. 7).

LDA provided assignment results and the percentage of correct classification (HR \%) to discriminate the sexes of D. magna populations (Table 3). At the individual level, a well supported discrimination was given for 194 of the 248 males and females. In males, the hit ratio for assignment to the correct group was $71 \%$ (17 of 24) for HDT, 64\% (14 of 22) for JLJ, 100\% for NGS and 77\% (17 of 22) for TB. In females, the hit ratio for assignment to the correct group was $81 \%$ (39 of 48 ) for HDT, $88 \%$ (35 of 40) for JLJ, 86\% (38 of 44) for NGS, and $65 \%$ (26 of 40) for TB. 


\begin{tabular}{|c|c|c|c|c|c|c|c|c|c|}
\hline & HDTơ & JLJ & NGS ô & ТВ & HDT우 & JLJㅇ & NGS 9 & $\mathrm{~TB}$ 우 & $\mathrm{HR} \%$ \\
\hline HDTô & 17 & 6 & & & 1 & & & & $71 \%$ \\
\hline JLJ đ̋ & 1 & 14 & & 4 & 1 & 1 & & 1 & $64 \%$ \\
\hline NGS ${ }^{\star}$ & & & 8 & & & & & & $100 \%$ \\
\hline TB $0 \hat{~}$ & 1 & 2 & 1 & 17 & & & & 1 & $77 \%$ \\
\hline HDT 9 & & 1 & & 1 & 39 & 2 & 3 & 2 & $81 \%$ \\
\hline JLJ $q$ & & & & & 1 & 35 & & 4 & $88 \%$ \\
\hline NGS 9 & & & & & 1 & 3 & 38 & 2 & $86 \%$ \\
\hline TB $q$ & & & & & 3 & 8 & 3 & 26 & $65 \%$ \\
\hline
\end{tabular}

Table 3. Specimen assignment in the LDA of sexes of D. magna populations (HDT, JLJ, NGS, and TB). Original groups are along the rows, predicted groups are along the columns. The hit ratio $(\mathrm{HR} \%)$ is also given for each groups.
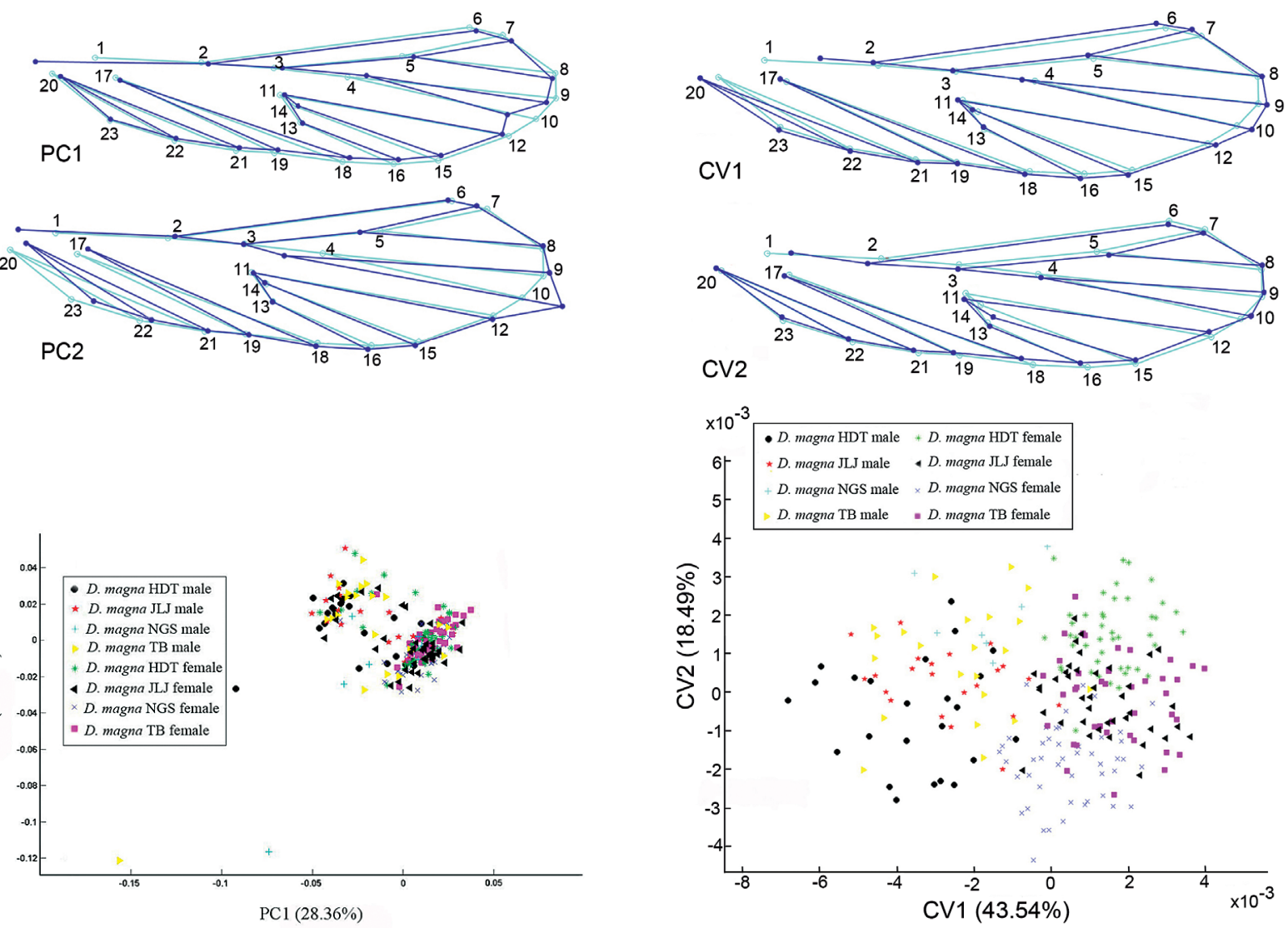

Fig. 6. Plots of the first two PCs (PC1 and PC2) obtained in the principal component analysis of the sexes of D. magna populations (HDT, JLJ, NGS, and TB). Wireframe graphs illustrate the shape variations associated with PC1 and PC2. A dark blue wireframe graph (solid dots) is compared with the overall mean shape (bright blue, open dots).

To estimate allometric effect, multivariate regression of shape variable (CV1) was used on centroid size. The results show that the allometric effect accounted for $16.91 \%$ of the total shape variance $(P<0.0001)$.

Fig. 7. Scatter plots showing scores on the first two canonical variables for the sexes of D. magna specimens. Wireframe graphs illustrate the shape changes associated with CV1 and CV2. A dark blue wireframe graph (solid dots) is compared with the overall mean shape (bright blue, open dots).

Because of the wing sexual dimorphism of $D$. mag$n a$, the following analyses were conducted separately on the males and females from four localities, respectively. 


\begin{tabular}{lrrrrl}
\hline & HDT & JLJ & NGS & TB & HR\% \\
\hline HDT & 43 & 1 & 1 & 3 & $90 \%$ \\
JLJ & 0 & 37 & 0 & 3 & $93 \%$ \\
NGS & 1 & 1 & 40 & 2 & $91 \%$ \\
TB & 2 & 4 & 3 & 31 & $78 \%$ \\
\hline
\end{tabular}

Table 4. Specimen assignment in the LDA of only the females in D. magna populations (HDT, JLJ, NGS, and TB). Original groups are along the rows, predicted groups are along the columns. The hit ratio (HR\%) is also given for each groups.
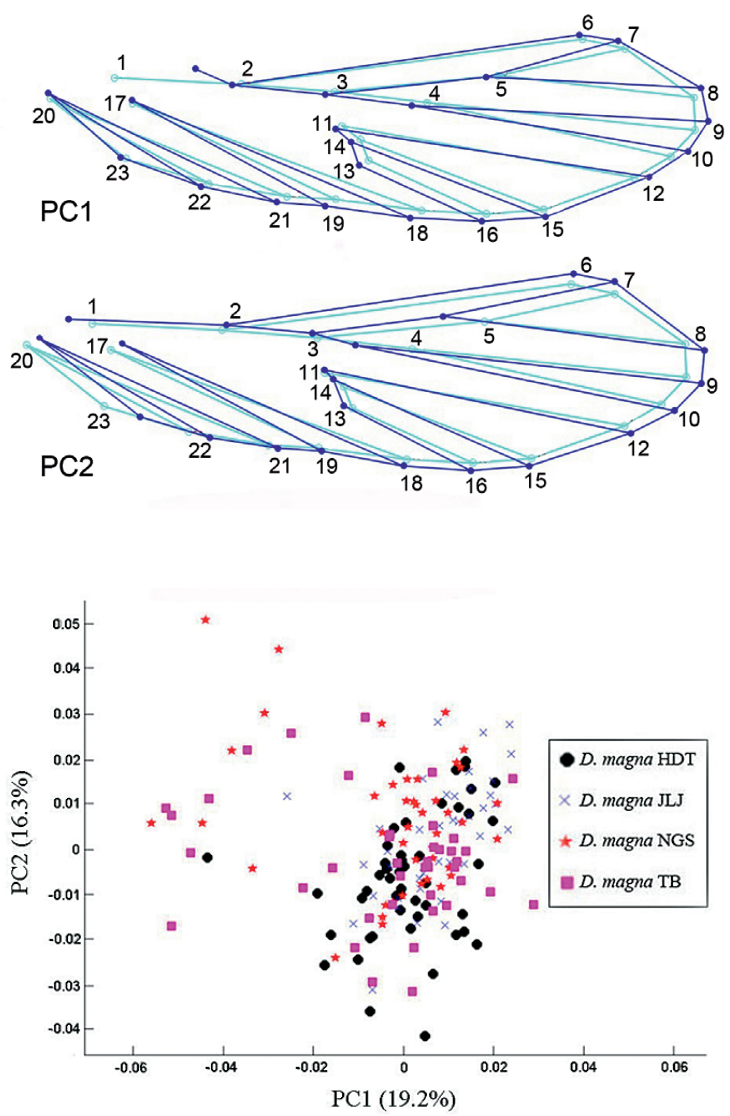

Fig. 8. Scatter plots showing scores on the first two PCs and deformed grids along each PC for females of D. magna populations. A dark blue wireframe graph (solid dots) is compared with the overall mean shape (bright blue, open dots).

Wing size variation among populations of D. magna

In males, the ANOVA on centroid sizes of wings does not differ significantly among the four populations

$(F(3,72)=2.589 ; P=0.059)$ and no post-hoc LSD pair-wise comparisons were significant on centroid sizes (Table 1). However, the males from NGS have a smaller centroid size than other populations (Fig. 3).

In females, a remarkable difference was found among the four populations (ANOVA: $F(3,168)=8.569 ; P=$ $0.000)$. The LSD test after Bonferroni correction on centroid sizes shows that NGS has the smallest centroid size $(P<0.006)$, differing significantly from other $D$. magna populations. No significant difference was found among the other three populations (PHDT/ $\mathrm{JLJ}=0.417 ; P \mathrm{HDT} / \mathrm{TB}=0.859 ; P \mathrm{JLJ} / \mathrm{TB}=0.344)$ (Table 1, Fig. 3).

Wing shape variation among populations of D. magna

In males, wing shape does not show significant difference among the four populations (MANOVA: $F(3,72)$ $=1.37 ; P=0.089>0.05$ ).

In females, more than $35 \%$ of the wing shape variation was described in $\mathrm{PC} 1$ and $\mathrm{PC} 2$ (Fig. 8). The scatter plots from PC1 (19.2\%) and PC2 (16.3\%) show a high degree of overlap and cluster of individuals from different localities. Most specimens clustered together on the right of scatter plots, only one specimen from HDT, a few individuals from NGS and TB were on the left of scatter plots (Fig. 8). The greatest shape variation associated with $\mathrm{PC} 1$ primarily involved in the elongation of the distal part of the wing, the expansion of the posterior margin of the wing and the furcation of veins Sc and R. PC2 represented an elongation of the anterior and distal parts of the wing and an expansion of the posterior margin of the wing (Fig. 8).

Significant shape differences in female wings were found among the four geographic populations (MANOVA: $F(3,168)=3.95, P=0.0058<0.05)$. The two axes of CVA scatter plots, CV1 (52.6\%, Wilks' $\lambda=0.0843$; $P<0.0000)$ and CV2 (33.7\%, Wilks' $\lambda=0.2668 ; P<$ 0.001 ), show that TB partly overlaps with NGS, HDT, and JLJ at the centre of the scatter plots. Overall, individuals from the same population were clustered together and populations from different localities were placed close to each other, with a low degree of overlap 

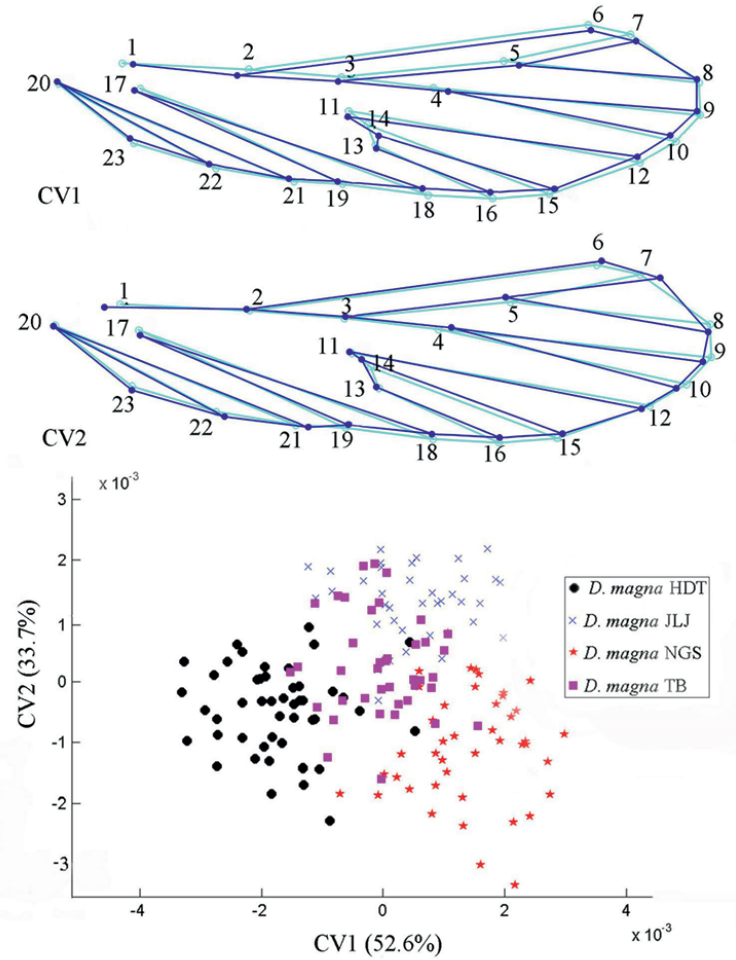

Fig. 9. Scatter plots from the CVA showing shape differentiation in females of D. magna populations. Shape changes associated with $\mathrm{CV} 1$ and $\mathrm{CV} 2$ are shown. A dark blue wireframe graph (solid dots) is compared with the overall mean shape (bright blue, open dots).

(Fig. 9). Shape changes associated with CV1 represented a construction of the anterior and posterior margins of the wing. CV2 reflected a construction of the distal part of the wing (Fig. 9).

The females of the four D. magna populations were well separated from each other in the LDA, indicating that the wing shape has a certain inter-population discrimination power. The assignment by the leave-oneout cross-validation showed that $88 \%$ of the females were correctly assigned to their groups (Table 4). The percentage of correct classification (HR\%) was $90 \%$ (43 of 48) for HDT, 93\% (37 of 40) for JLJ, 91\% (40 of 44) for NGS, and $78 \%$ (31 of 40) for TB (Table 4).

\section{Discussion}

Sexual dimorphism is a common phenomenon in many insect taxa and is considered one of the most interesting sources of phenotypic variation (Fairbairn and Preziosi, 1976). Sexual dimorphism in wing morphology may be an adaptive response to flight and behavioral activities, as in dipterans and parasitoids (McLachlan, 1986; Gidaszewski et al., 2009; Benítez et al., 2013). In D. magna the wing size and shape differ significantly between the sexes, with the centroid size of female wings remarkably larger than the male's, indicating that a female-biased sexual size dimorphism exists, in accordance with approximately $80 \%$ of investigated insect species (Honěk, 1993; Teder and Tammaru, 2005). This kind of sexual size dimorphism is primarily ascribed to the strong fecundity advantage of larger females (Allen et al., 2011) and the sensitivity to environmental conditions of females (Teder and Tammaru, 2005). In addition, small size of males may be related with protandry (Jarošík and Honek, 2007), because the faster-developed males can increase the frequency and success of mating or increase the opportunity to access preferred territories (Allen et al., 2011). Significant difference in wing shape is also present between the sexes of $D$. magna and allometry is an important component of sexual shape dimorphism in the wings. The difference is considered to be associated with flight behavior (Gilchrist, 1990; Gidaszewski et al., 2009; Allen et al., 2011). In general, male insects usually bear shorter and narrower wings because of the fast-beating frequency for courtship and mating, whereas female insects have evolved longer and broader wings to allow them much more easily to find oviposition sites with heavier metsomas carrying eggs (Gilchrist, 1990; Honěk, 1993; Blanckenhorn, 2000; Gidaszewski et al., 2009).

Speciation is an evolutionary process by which new species arise and is considered one of the main ways by which organisms adapt to exploit the diversity of environments available to them (White, 1978; Singh, 2012). Rapid parapatric speciation on the time scale of a few hundred to a few thousand generations is plausible without the need of complete geographic isolation, even when neighboring populations exchange several individuals each generation (Gavrilets et al., 2000). In the present study, wing morphology of D. baiyunsha$n a$ differs significantly from that of D. magna, supporting the previous research that the former is an evolutionarily independent entity (Zhong and Hua, 2013). In the geographic distribution aspect, D. baiyunshana is located in the hinterland of the Funiu Mountains continuously overlapping with $D$. magna from eastern Qinling Mountains in a small region.

The variation of wing morphology reflects the evolutionary history with a potential influence of environ- 
mental factors, mainly climatic changes (Velzen et al., 2013; Perrard et al., 2014) and geological events (McCulloch et al., 2009). In the present study, significant wing size and shape variations were found only in the females of three D. magna populations from the Qinling Mountains (HDT, JLJ, and TB) and one from the Daba Mountains (NGS). The Qinling Mountains, the biogeographical boundary between the Oriental and Palearctic Regions in central China, also the boundary of the north warm temperate and the north subtropical zones, has been modified greatly in topography under the influence of the East Asian monsoon climate due to the rapid uplift of the Qinghai-Tibetan Plateau during the late Miocene (An et al., 2001; Zhang et al., 2006; Dong et al., 2011; Jorge et al., 2011). The Daba Mountains arose in the Indosinian-Yanshanian orogenies of mid-late Jurassic period, and fixed in the Himalayan orogenic belt during the Miocene-Pleistocene (Wang et al., 2004). Along with the uplift of the Qin-Ba Mountains, the climate of the north Qinling Mountains has gradually changed from subtropics to temperate type (Ying, 1994; Wang and Yan, 2011). The Mecoptera were recorded as early as the Lower Permian and were very prosperous from late Permian to whole Mesozoic era based on fossil records (Byers and Thornhil, 1983; Grimaldi and Engel, 2005; Sun et al., 2007). D. magna is endemic to the Qin-Ba mountain regions and evolved approximately during the late $\mathrm{Mi}$ ocene at 7.5 million years ago (Hu et al., 2015). It has experienced dramatic tectonic uplift during the late Miocene-late Pleistocene in the Qin-Ba Mountains. Due to its weak flight ability, the dispersal of D. mag$n a$ is severely limited even by a narrow zone of unsuitable habitat, such as the Hanshui River and the series of basins between the Qinling Mountains and Daba Mountains, since the scorpionflies live in the mountain area at high elevations (above $1300 \mathrm{~m}$ ) and are unable to tolerate the high temperature at the low elevations, so that it is almost impossible for them to pass the Hanshui River under natural conditions. In other words, the Hanshui River is likely a strong geographical barrier to restrict the dispersal of the scorpionflies, thus preventing the gene flow between populations. However, whether reproductive isolation is leading allopatric speciation in different geographic populations need further research.

\section{Acknowledgements}

Mei Liu and Na Ma contributed equally to this work. We thank Wen Zhong, Qingxiao Chen, and Lu Jiang for specimen collec- tion and Yanyan Feng, Jing Chen and Yanqing Hu for assistance in software application. Our special thanks go to the two reviewers, Mateus Pepinelli and Thibaut De Meulemeester, for critically reviewing the manuscript. This research was financially supported by the National Natural Science Foundation of China (Grant Nos. 31172125 and 31301898), the China Postdoctoral Science Foundation (Grant Nos. 2012M520085 and 2013T60893), and the Postdoctoral Research Program of Shaanxi.

\section{References}

Adams DC, Rohlf FJ, Slice DE. 2013. A field comes of age: geometric morphometrics in the 21st century. Hystrix, the Italian Journal of Mammalogy 24: 7-14.

Allen CE, Zwaan BJ, Brakefield PM. 2011. Evolution of sexual dimorphism in the Lepidoptera. Annual Review of Entomology 56: 445-464.

An ZS, Kutzbach JE, Prell WL, Porter SC. 2001. Evolution of Asian monsoons and phased uplift of the Himalaya-Tibetan plateau since Late Miocene times. Nature 411: 62-66.

Aytekin MA, Terzo M, Rasmont P, Çağatay N. 2007. Landmark based geometric morphometric analysis of wing shape in Sibiricobombus Vogt (Hymenoptera: Apidae: Bombus Latreille). Annales de la Société Entomologique de France (N.S.) 43: 95-102.

Baracchi D, Dapporto L, Turillazzi S. 2011. Relevance of wing morphology in distinguishing and classifying genera and species of Stenogastrinae wasps. Contributions to Zoology 80: 191-199.

Barão KR, Gonçalves GL, Mielke OH, Kronforst MR, Moreira GR. 2014. Species boundaries in Philaethria butterflies: an integrative taxonomic analysis based on genitalia ultrastructure, wing geometric morphometrics, DNA sequences, and amplified fragment length polymorphisms. Zoological Journal of the Linnean Society 170: 690-709.

Benítez HA, Bravi R, Parra LE, Sanzana MJ, Sepúlveda-Zúñiga E. 2013. Allometric and non-allometric patterns in sexual dimorphism discrimination of wing shape in Ophion intricatus: Might two male morphotypes coexist? Journal of Insect Science 13: 1-10.

Blanckenhorn WU. 2000. The evolution of body size: what keeps organisms small? Quarterly Review of Biology 75: 385-407.

Bookstein FL. 1991. Morphometric tools for landmark data. Cambridge: Cambridge University Press.

Bookstein FL. 1996. Combining the tools of geometric morphometrics. Pp. 131-151 in: Marcus LF, Corti M, Loy A, Nayulor GJP, Slice DE, eds, Advances in morphometrics. New York: Plenum Press.

Byers GW, Thornhill R. 1983. Biology of the Mecoptera. Annual Review of Entomology 28: 203-228.

Chou I, Ran RB, Wang SM. 1981. Study on the classification of Chinese Mecoptera (I, II). Entomotaxonomia 3: 1-22.

Dong YP, Zhang GW, Neubauer F, Liu XM, Genser J, Hauzenberger C. 2011. Tectonic evolution of the Qinling orogen, China: review and synthesis. Journal of Asian Earth Sciences 41: 213-237.

Dryden IL, Mardia KV. 1998. Statistical analysis of shape. New York: Wiley. 
Fairbairn DJ, Preziosi RF. 1976. Sexual selection and the evolution of the sexual size dimorphism in the waterstrider, Aquarius remigis. Evolution 50: 1549-1559.

Francuski LJ, Vujić A, Kovačević A, Ludoški J, Milankov V. 2009. Identification of the species of the Cheilosia variabilis group (Diptera, Syrphidae) from the Balkan Peninsula using wing geometric morphometrics, with the revision of status of C. melanopa redi Vujić, 1996. Contributions to Zoology 78: $129-140$.

Gavrilets S, Li H, Vose MD. 2000. Patterns of parapatric speciation. Evolution 54: 1126-1134.

Gerard M, Michez D, Fournier D, Maebe K, Smagghe G, Biesmeijer JC, De Meulemeester T. 2015. Discrimination of haploid and diploid males of Bombus terrrestris (Hymenoptera; Apidae) based on wing shape. Apidologie 46: 644-653.

Gidaszewski NA, Baylac M, Klingenberg CP. 2009. Evolution of sexual dimorphism of wing shape in the Drosophila melanogaster subgroup. BMC Evolutionary Biology 9: 110.

Gilchrist GW. 1990. The consequences of sexual dimorphism in body size for butterfly flight and thermoregulation. Functional Ecology 4: 475-487.

Grimaldi D, Engel MS. 2005. Evolution of the insects. Cambridge: Cambridge University Press.

Grodnitsky DL. 1999. Form and function of insect wings: the evolution of biological structures. Baltimore, USA: The Johns Hopkins University Press.

Haas HL, Tolley KA. 1998. Geographic variation of wing morphology in three Eurasian populations of the fruit fly, Drosophila lummei. Journal of Zoology 245: 197-203.

Honěk A. 1993. Intraspecific variation in body size and fecundity in insects: a general relationship. Oikos 66: 483-492.

Hou XY, Hua BZ. 2008. Structures of the female reproductive systems in Panorpidae (Mecoptera) with remarks on their taxonomic significance. Acta Zootaxonomica Sinica 33: 427-434.

Hu GL, Yan G, Xu H, Hua BZ. 2015. Molecular phylogeny of Panorpidae (Insecta: Mecoptera) based on mitochondrial and nuclear genes. Molecular Phylogenetics and Evolution 85:22-31.

Hua BZ, Chou I. 1997. The Panorpidae (Mecoptera) of Funiu Mountain in Henan Province. Entomotaxonomia 19: 273-278.

Huberty CJ, Olejnik S. 2006. Applied MANOVA and discriminant analysis. 2 nd ed. Hoboken (NJ): Wiley.

IBM Corporation. 2010. IBM SPSS Statistics for Windows, version 19.0. Armonk, NY: IBM Corporation.

Jarošík V, Honek A. 2007. Sexual differences in insect development time in relation to sexual size dimorphism. Pp. 205-211 in Fairbairn DJ, Blanckenhorn WU, Székely T, eds, Sex, size and gender roles: Evolutionary studies of sexual size dimorphism. Oxford: Oxford University Press.

Jones JR. 2010. Intraspecific variation in a scorpionfly newly recorded from Texas and the state of taxonomy of North American Panorpidae (Mecoptera). Psyche 2010: 152981.

Jorge LR, Cordeiro-Estrela P, Klaczko LB, Moreira GRP, Freitas AVL. 2011. Host-plant dependent wing phenotypic variation in the neotropical butterfly Heliconius erato. Biological Journal of the Linnean Society 102: 765-774.

Klingenberg CP. 2011. MorphoJ: an integrated software package for geometric morphometrics. Molecular Ecology Resources 11: 353-357.
Klingenberg CP, McIntyre GS. 1998. Geometric morphometrics of developmental instability: analyzing patterns of fluctuating asymmetry with Procrustes methods. Evolution 52: 1363-1375.

Liang ZX. 2002. The natural environment change of Qin-Ba Mountains during the period of history. Collections of Essays on Chinese Historical Geography 17: 39-47.

Ma N, Hu GL, Zhang JX, Hua BZ. 2014. Morphological variation of the scorpionfly Panorpa obtusa Cheng (Mecoptera: Panorpidae) with a new synonym. PLoS ONE 9: e108545.

Ma N, Liu SY, Hua BZ. 2011. Morphological diversity of male salivary glands in Panorpidae (Mecoptera). European Journal of Entomology 108: 493-499.

Mayr E. 1963. Animal species and evolution. Cambridge: Harvard University Press.

McCulloch, GA, Wallis, GP, Waters, JM. 2009. Do insects lose flight before they lose their wings? Population genetic structure in subalpine stoneflies. Molecular Ecology, 18: 40734087.

McLachlan AJ. 1986. Sexual dimorphism in midges: strategies for flight in the rain-pool dweller Chironomus imicola (Diptera: Chironomidae). The Journal of Animal Ecology 55: 261-267.

McPeek MA. 1990. Behavioral differences between Enallagma species (Odonata) influencing differential vulnerability to predators. Ecology 71: 1714-1726.

Michaux B. 1989. Morphological variation of species through time. Biological Journal of the Linnean Society 38: 239-255.

Milliken GA, Johnson DE. 2009. Analysis of messy data. Vol. 1: Designed Experiments. 2nd ed. New York: CRC Press.

Nedeljković Z, Ačanski J, Vujić A, Obreht D, Đan M, Ståhls G, Radenković S. 2013. Taxonomy of Chrysotoxum festivum Linnaeus, 1758 (Diptera: Syrphidae) - an integrative approach. Zoological Journal of the Linnean Society 169: 84102.

Neto JM, Gordinho L, Belda EJ, Marín M, Monrós JS, Fearon P, Crates R. 2013. Phenotypic divergence among West European populations of reed bunting Emberiza schoeniclus: the effects of migratory and foraging behaviours. PLOS ONE 8: e63248.

Nie XN, Hua BZ. 2004. Panorpidae (Mecoptera) from Huoditang in Qinling Mountains. Entomotaxonomia 26: 187-192.

Palmer M. 2002. Landmark-based morphometric analysis of two sibling species of the genus Asida (Coleoptera, Tenebrionidae). Contributions to Zoology 70: 1-10.

Pepinelli M, Spironello M, Currie DC. 2013. Geometric morphometrics as a tool for interpreting evolutionary transitions in the black fly wing (Diptera: Simuliidae). Zoological Journal of the Linnean Society 169: 377-388.

Perrard A, Baylac M, Carpenter JM, Villemant C. 2014. Evolution of wing shape in hornets: why is the wing venation efficient for species identification? Journal of Evolutionary Biology 27: 2665-2675.

R Core Team. 2013. R: A language and environment for statistical computing. R Foundation for Statistical Computing. Vienna, Austria. Available at http://www.R-project.org.

Riedel A, Sagata K, Suhardjono YR, Tänzler, R, Balke M. 2013. Integrative taxonomy on the fast track - towards more sustainability in biodiversity research. Frontiers in Zoology 10: 15.

Rohlf FJ. 2004. tpsDig2, version 2.0. Available at http://life.bio. sunysb.edu/morph/. 
Rohlf FJ. 2006. tpsRelw, version 1.44. Available at http://life. bio.sunysb.edu/morph/.

Rohlf FJ, Loy A, Corti M. 1996. Morphometric analysis of Old World Talpidae (Mammalia, Insectivora) using partial-warp scores. Systematic Biology 45: 344-362.

Rohlf FJ, Slice D. 1990. Extensions of the Procrustes method for the optimal superimposition of landmarks. Systematic Zoology 39: 40-59.

Sheets HD. 2012. IMP software series. Canisius College, Buffalo, New York.

Singh BN. 2012. Concepts of species and modes of speciation. Current Science 103: 784-790.

Stillwell RC, Blanckenhorn WU, Teder T, Davidowitz G, Fox CW. 2010. Sex differences in phenotypic plasticity affect variation in sexual size dimorphism in insects: from physiology to evolution. Annual Review of Entomology 55: 227-245.

Sun JH, Ren D, Huang JD. 2007. Current knowledge of research on Mecoptera fossils in China. Acta Zootaxonomica Sinica 32: 881-889.

Teder T, Tammaru T. 2005. Sexual size dimorphism within species increases with body size in insects. Oikos 108: 321-334.

Thornhill R. 1979. Adaptive female-mimicking behavior in a scorpionfly. Science 205: 412-414.

Thornhill R. 1980. Competition and coexistence among Panorpa scorpionflies (Mecoptera: Panorpidae). Ecological Monographs 50: 179-197.

Velzen RV, Wahlberg N, Sosef MSM, Bakker FT. 2013. Effects of changing climate on species diversification in tropical forest butterflies of the genus Cymothoe (Lepidoptera: Nymphalidae). Biological Journal of the Linnean Society 108: 546-564.

Wang Y, Yan JP. 2011. Evolution of the Qinling Mountain and the impact factors. Journal of Northwest University (Natural Science Edition) 41: 163-169.
Wang ZC, Zou CN, Tao SZ, Li J, Wang SQ, Zhao CY. 2004. Analysis on tectonic evolution and exploration potential in Dabashan foreland basin. Acta Petrolei Sinica 25: 23-28.

Ward PH. 1979. Structural variation in the genitalia of the Panorpa alpina-complex (Mecoptera). Systematic Entomology 4: 71-79.

Ward PH. 1983. Scorpion-flies of the Panorpa cognata-complex in the western Palaearctic region (Mecoptera). Journal of Natural History 17: 627-645.

White MJD. 1978. Modes of speciation. San Francisco: WH Freeman.

Ying T. 1994. An analysis of the flora of Qinling Mountain range: its nature, characteristics and origins. Acta Phytotaxonomica Sinica 32: 389-410.

Yuan JH, Cheng FY, Zhou SL. 2012. Genetic structure of the tree peony (Paeonia rockii) and the Qinling Mountains as a geographic barrier driving the fragmentation of a large population. PLOS ONE 7: e34955.

Zelditch ML, Swiderski DL, Sheets HD, Flink WL. 2004. Geometric morphometrics for biologists: A primer. San Diego: Elsevier Academic Press.

Zhang PZ, Zheng DW, Yin GM, Yuan DY, Zhang GL, Li CY, Wang ZC. 2006. Discussion on late Cenozoic growth and rise of northeastern margin of the Tibetan Plateau. Quaternary Science 26: 5-13.

Zhong W, Hua BZ. 2013. Dicerapanorpa, a new genus of East Asian Panorpidae (Insecta: Mecoptera: Panorpidae) with descriptions of two new species. Journal of Natural History 47: 1019-1046.

Received: 7 January 2015

Revised and accepted: 16 July 2015

Published online: 12 January 2016

Editor: J.C. Biesmeijer 